\title{
Vandortuzumab Vedotin
}

National Cancer Institute

\section{Source}

National Cancer Institute. Vandortuzumab Vedotin. NCI Thesaurus. Code C116748.

An antibody-drug conjug ate (ADC) composed of a humanized monoclonal antibody directed ag ainst the six transmembrane epithelial antigen of the prostate 1 (STEAP1), and conjug ated, via a protease-cleavable peptide linker, to monomethyl auristatin $\mathrm{E}$ (MMAE), an auristatin derivative and a potent microtubule disrupting agent, with potential antineoplastic activity. Upon administration of vandortuzumab vedotin, the monoclonal antibody moiety of vandortuzumab vedotin binds to STEAP1-expressing tumor cells and is internalized, thereby delivering MMAE intracellularly. Proteolytic cleavage releases MMAE, which then binds to tubulin and inhibits its polymerization, resulting in G2/M phase arrest and tumor cell apoptosis. ST EAP1, a tumor-associated antigen (TAA), is overexpressed in a variety of cancer cell types. 